\title{
EXPLORE
}

\section{Aplikasi Argaria Market Berbasis Mobile Untuk Mempersingkat Distribusi Penjualan Hasil Komoditi Laut Di Kepulauan Aru}

\author{
Fenty Ariani, Charles Evan Djabumir, Ayu Kartika Puspa, Freddy Nur Afandi \\ Program Studi Sistem Informasi \\ Fakultas Ilmu Komputer \\ Universitas Bandar Lampung \\ Bandar Lampung, Indonesia \\ fenty.ariani@ubl.ac.id, charles.17411014@student.ubl.ac.id, erlangga@ubl.ac.id, ayukartikapuspa@ubl.ac.id, \\ freddsie@yahoo.com
}

\begin{abstract}
Abstrak-Perkembangan teknologi kini semakin berkembang dalam semua bidang, hal ini merupakan peluang bagi pelaku usaha dalam memasarkan product. peluang ini dapat di manfaat kan bagi pelaku usaha komoditi laut untuk memasarkan hasil komoditi laut yang diperoleh dengan system e-commerce, sehingga pasar yang dihasilkan dapat menjadi lebih luas dan dapat mempersingkat dalam rantai distribusi komoditi hasil laut, seperti yang kita ketahui pemasaran product hasill laut masih dilakukan dengan cara manual sehingga konsument yang ingin membeli dalam jumlah besar harus turun lapangan untuk melihat hasil laut apa saja yang tersedia, selain itu panjangnya distribusi dalam penjualan membuat margin yang diperoleh oleh nelayan sangat kecil. Untuk mengatasi masalah tersebut diperlukan system yang dapat memperluas pasar dan juga dapat memperpendek rantai distribusi yang terjadi, sehingga margin yang diperoleh nelayan cukup besar dan juga konsument dapat melihat product komoditi hasil laut apa saja yang tersedia dengan hanya melalui smamrtphone. Tujuan penelitian ini yaitu mempersingkat distribusi penjualan hasil komoditi laut di kepulauan aru serta Meningkatan hasil penjualan dalam sektor hasil laut dan memperluas pasar daya jual komoditi hasil laut.

Kata Kunci: Komoditi Hasil Laut, Nelayan, E-Commerce
\end{abstract}

\section{Pendahuluan}

Indonesia merupakan Negara yang memiliki sumber daya alam yang melimpah salah satunya ialah sumber daya hasil laut, sumber daya hasil laut merupakan komuditas andalan bagi Indonesia. Dalam konteks global, Indonesia memiliki kondisi geografis yang strategis dititik silang perdagangan dunia dengan potensi laut yang luas menjadikan Indonesia sebagai penghasil sumber daya hasil komoditi laut yang besar dan dapat menjadikan Indonesia sebagai pasar dengan produk hasil komoditi laut yang sangat prospektif. [1] sebab itu masyarakat Indonesia yang tinggal didaerah pesisir memiliki profesi sebagai nelayan. Daerah Kepulauan Aru memiliki hasil komoditi laut yang besar, kita dapat menemukan berbagai macam jenis hasil laut seperti ikan, rumput laut, teripang, lambung ikan, telur ikan, kepiting bakau dan masih banyak lagi hasil laut yang bisa kita temukan.

Pemasaran hasil komoditi laut tidak hanya mencangkup dalam Negeri namun juga luar Negeri, permintaan pasar yang tinggi menjadi salah satu sektor yang penting bagi perekonomian Indoneisa. Namun disisi lain banyak masyarakat yang tidak di untungkan akibat permasalahan rantai distribusi penjualan produk hasil laut yang cukup panjang antara Nelayan dan konsumen, salah satunya ialah panjangnya rantai distribusi dari nelayan ke konsumen, hal ini diakibatkan karena sebagian besar distribusi hasil laut didominasi oleh pedagang baik pedagang pengumpul tingkat desa dan kecamatan, pedagang besar, maupun eksportir yang sering kali tidak memberikan nilai tambah apa pun terhadap produk yang akan dipasarkan, namun tetap mengambil margin. Keadaan ini mengakibatkan keuntungan bisnis hasil laut masih banyak yang dinikmati oleh pedagang bukan oleh Nelayan, dan tentu saja ini akan berimbas langsung ke konsumen (end user).

Internet memiliki kemampuan untuk melakukan berbagai kegiatan termasuk memasarkan produk online kepada siapa saja yang membutuhkan dan terhubung ke internet. Ini disebut e-marketing, pemasaran elektronik yang menghadirkan banyak kemudahan bagi perusahaan, pelanggan, dan mitra bisnis. [2] Mengingat kita sudah berada di zaman cutting edge yang dipenuhi dengan teknologi dimana teknologi sangat banyak membantu keseharian manusia, perangkat Portable merupakan salah satu teknologi yang withering dekat dengan manusia, pertukaran informasi dapat dilakukan secara cepat (realtime) tidak hanya itu saat ini masyarakat dapat 
berbelanja kebutuhan sehari-hari hanya melalui perangkat versatile. Sehingga waktu yang dihasilkan play on words sangat efisien, perangkat portable sangat berguna dalam keseharian manusia, Oleh karena itu penulis ingin merancang sebuah "Aplikasi argaria Advertise Berbasis Portable Untuk Mempersingkat Rantai Distribusi Penjualan Hasil Komoditi Laut Di Kepulauan Aru" sehingga dapat membantu dalam meningkatkan hasil produktifitas dalam sektor penjualan hasil laut dan mempermudah rantai pasok antara nelayan dan konsumen. Adapun Batasan masalah Pada system yang digunakan user hanya dapat melakukan penampilan

\section{Dasar Teori}

Perdagangan elektronik atau yang disebut juga ecommerce adalah penggunaan jaringan komunikasi dan komputer untuk melaksanakan proses bisnis. Pandangan populer dari e-commerce adalah penggunaan internet dan komputer dengan browser Web untuk membeli dan menjual produk. Jony Wong [3] E-commerce adalah pembelian, penjualan, dan pemasaran barang serta jasa melalui sistem elektronik seperti radio, televisi, dan jaringan komputer atau internet. Selain itu dalam ecommerce terdapat beberapa jenis seperti B2B, B2C, C2C, C2B, C2A, B2A, O2O. Marketplace merupakan pihak perantara yang mengakomodasi pihak penjual dan pihak pembeli didalam dunia maya. Situs commercial center akan menjadi layaknya pihak ketiga dalam transaksi online dengan menyediakan fitur penjualan serta fasilitas pembayaran yang aman. Commercial center sendiri bisa kita artikan sebagai suatu division store-nya online store. Dalam commercial center terdapat beberapa jenis seperti marketplace murni dan marketplace konsinyasi, Portable commerce adalah bagian dari e-commerce yang terjadi secara eksklusif melalui perangkat bergerak seperti smartphone atau tablet. Selain pembelian dan penjualan barang dan jasa, bentuk perdagangan web ini juga termasuk pembayaran melalui smartphone dan tablet (pembayaran versatile). Selainwitu, M-Commerce juga mentransfer kepemilikan dan hak penggunaan dan memulai transaksi bisnis. Terdapat Komponen Mobile Commerce seperti: Periklanan seluler, Pembayaran Seluler, Pemesanan dan reservasi, Mobile Banking, Layanan pembayaran SMS, Aplikasi Seluler

Mobile merupakan sebuah sistem perangkat lunak yang memungkinkan setiap pemakai melakukan mobilitas dengan perlengkapan PDA-asisten digital perusahaan pada telepon genggam atau seluler. Android dan iOS

\section{Metodologi}

Penelitian ini menggunakan jenis penelitian rekayasa software yang menerapkan ilmu pengetahuan menjadi satu rancangan guna mendapatkan kinerja yang sesuai dengan persyaratan yang telah ditentukan. Metode pengumpulan data menggunakan data Sekunder dengan melakukan beberapa cara, sebagai berikut observasi dan wawancara. Metode Analisis yang digunakan ialah Metode Kualitatif untuk merancang sistem argaria Market berbasis ECommerce. Dengan metode ini penelitian melakukan wawancara dan observasi secara online, agar mendapatkan informasi yang diperlukan dalam product, memasukan item kedalam keranjang, melihat detail transaksi dan melakukan pembayaran. Sedangkan untuk admin hanya dapat melakukan proses input data, melihat stock data, update data, hapus data, dan juga dapat mengkonfirmasi pembayaran.

Dengan dilakukannya penelitian ini penulis berharap dapat membantu meningkatkan daya jual hasil laut khususnya di daerah Kepulauan Aru, memperluas pasar komoditi hasil laut, serta apat mempermudah dalam proses transaksi, Waktu yang dihasilkan menjadi lebih efisien.

merupakan sistem operasi mobile yang untuk saat ini merajai pasaran. Aplikasi mobile juga dikenal sebagai web app, online app, iPhone app atau smartphone app. Diagram ERD merupakan suatu bentuk diagram yang menjelaskan hubungan antara object - object data yang mempunyai hubungan antar relasi. ERD digunakan untuk Menyusun struktur data dan hubungan antar data, dan untuk mengambarkannya digunakan notasi, symbol, bagan,dan lain sebagainya. Use case digram merupakan diagram yang menggambarkan hubungan antara actor dengan system. Use case diagram bisa mendeskripsikan sebuah interaksi antara satu atau lebih actor dengan system yang akan dibuat. Manfaat dari use case sendiri ialah untuk mempermudah komunikasi dengan menggunakan domain expert dan juga end user serta memberikan kepastian pemahaman yang pas tentang requitment atau juga kebutuhan sebuah system. Activity Diagram merupakan rancangan aliran aktivitas atau aliran kerja dalam sebuah sistem yang akan dijalankan. Activity Diagram juga digunakankuntuk mendefinisikan atau mengelompokanlaluran tampilankdari sistemwtersebut. Activity Diagram memiliki komponenidengan bentuk tertentu yangkdihubungkan denganktanda panah. Panahptersebut mengarah ke-urutan aktivitas yang terjadi idari awal hingga akhir. Flowchart atau dalam bahasa Indonesia sering disebut dengan Diagram Alir ini berfungsi untuk menggambarkan proses-proses operasional yang terjadi didalam system sehingga mudah dipahami dan mudah dilihat berdasarkan urutan langkah dari suatu proses ke proses lainnya. Flowchart (bagan alir) adalah gambaran dalam bentuk diagram alir dari algoritma-algoritma dalam suatu program, yang menyatakan arah alur program tersebut.

membangun sistem argaria Market berbasis ECommerce.

Analisis dan kebutuhan data yang digunakan antara lain bisinis rule, analisis kebutuhan data dan informasi, tools yang digunakan, sistem yang dibangun. Perancangan sistem dalam penelitian ini menggunakan analsisa sistem berjalan dan perancangan sistem aplikasi. Pemodelan system yang digunakan pada penelitian ini ialah dengan menggunakan Diagram ERD, Use Case Diagram, Activity Diagram dan Flowchart. 


\section{Hasil dan Pembahasan}

Hasil dan pembahasan dari implementasi system ECommerce argaria Market Berbasis Mobile menggunakan android studio dan NodeJs. Pengujian system dari sisi pengembangan sangat diperlukan untuk mengidentifikasi dan meminimalisir kemungkinan masalah yang terjadi serta mengetahui fungsi system dapat berjalan dengan baik pada system sebelum system digunakan pada pengguna.

\section{Analisa}

Dari hasil pengamatan pada object penulis mengumpulkan sempel data Nelayan yang berada di kep. Aru. Di kepulauan aru hampir sebagaian besar penduduk memiliki profesi sebagai nelayan dan penulis memilih 4 orang Nelayan sebagai bahan perbandingan pada penelitian ini. Pada aplikasi ini terbagi menjadi dua bagian, bagian user dan bagian admin. Pada bagian user sistem yang tersedia ialah berbasis mobile, proses yang terjadi pada sistem user dapat dilihat pada gambar 1.

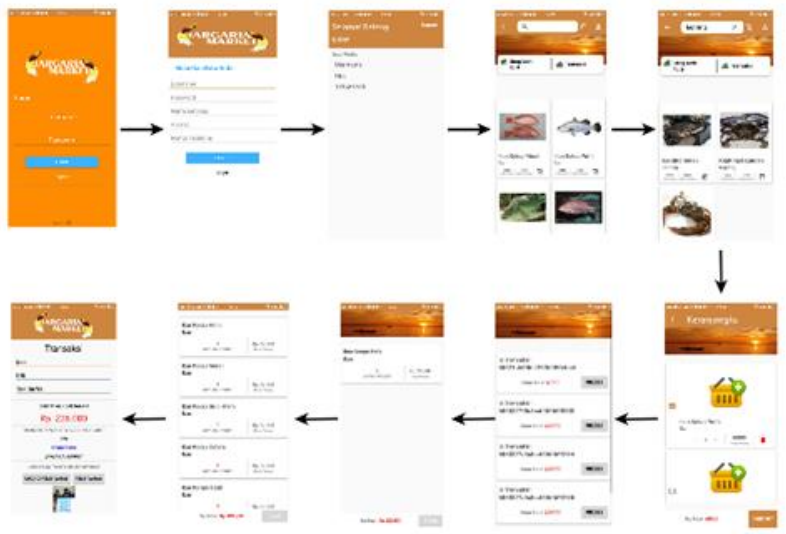

Gambar 1 Proses yang terjadi dalam Sistem argaria Market Mobile

Proses yang terjadi ialah user dapat login dengan memasukan username dan password, ika user belum memiliki akun maka user dapat mendaftar pada halaman register, setelah itu user akan dibawa pada halaman utama dimana user dapat mencari produk yang di inginkan melalui kolom search dan memasukannya pada keranjangku, item yang berada di keranjangku dapat dipilih sesuai dengan keinginan untuk dilanjutkan pada proses check out, setelah item berhasil melalui proses check out user akan ditampilkan halaman transaksi dan detail transaksi untuk melihat product yang di beli, dan melanjutkannya pada proses pembayaran dengan mengirim bukti pembayaran, dan menunggu konfirmasi admin untuk di proses lebih lanjut lagi.

Pada bagaian admin sistem yang disediakan berbasis website dimana admin dapat melakukan proses login, input produk, mengubah produk, menghapus produk serta mengkonfirmasi pembayaran yang telah dilakukan user. Proses tersebut dapat dilihat pada gambar 2 .

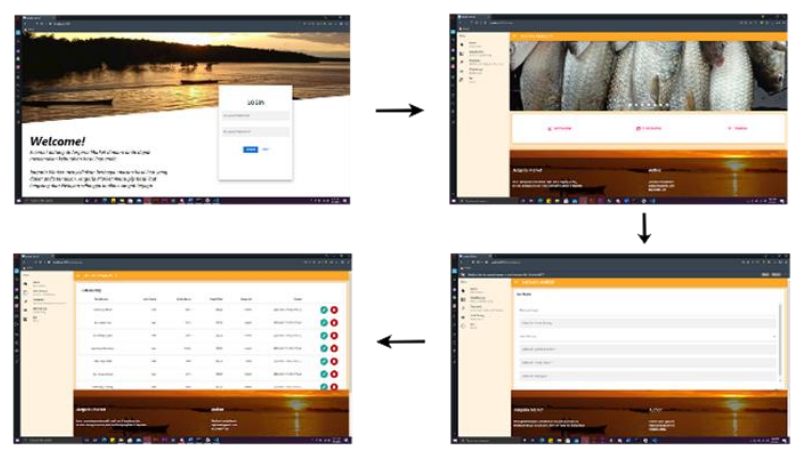

$\downarrow$

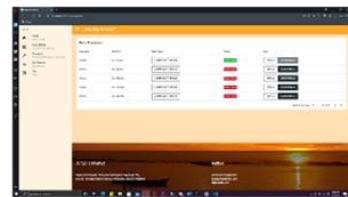

Gambar 2. Sistem Jaargaria Maarket Admin Berbasis Web 


\section{Kesimpulan}

1. Kesimpulan

Adapun kesimpulan pada penelitian ini yaitu Perancangan aplikasi argaria Market menggunakan Bahasa Pemograman JAVA dan database yang digunakan ialah MonggoDB. Sehingga didapatkan program aplikasi argaria Market yang dapat membantu dalam mendistribusikan hasil laut menjadi lebih mudah serta meningkatan dalam penjualan hasil laut. Pada Aplikasi argaria Market ini dapat memberikan informasi mengenai product - product hasil laut apa saja yang tersedia di kep. Aru. Selain itu pada aplikasi ini user dapat melakukan pencarian product, pemilihan product serta melakukan transaksi untuk pemesanan product, selain itu juga pada admin dapat menginput product, mengubah data product, menghapus product, serta dapat mengkonfirmasi pembayaran.

2. Saran

Berdasarkan permsalahan yang ada, penulis membrikan saran yang dapat kiranya dapat bermanfaat bagi masyarakat kep. Aru dalam meningkatkan kinerja penjualan pada hasil laut di daerah Kep. Aru. Saran - saran yang diberikan antara lain:

a. Untuk kelancaran dalam mengelolah aplikasi argaria market, perawatan computer dan perangkat keras lainnya serta perangkat lunak harus diperhatikan.

b. Untuk user yang akan menggunakan aplikasi argaria market harus mengikuti pelatihan terlebih dahulu agar tidak mengalami keliruan dan ketidak sesuaian dalam proses pengelolahan data.

c. Untuk menjaga data pada aplikasi argaria Market, disarankan untuk melakukan back-up data ke system penyimpanan lain dan perawatan pada system yang baik dan benar agar menghindari adanya kerusakan pada system aplikasi argaria market.

\section{Daftar Pustaka}

[1] S. B. Pamungkas, "Analisis Rantai Distribusi Komuditas Ikan Tangkap Perikanan Laut Di Kota Tegal," Analisi Rantai Distribusi Komuditas Ikan Tangkap Perikanan Laut Di Kota Tegal, p. 1, 2013.

[2] E. M. H. A. Y. A. Fenty Ariani, "Aplikasi E-Marketing Panglong Kayu Menggunakan Metode Colaborative Filtering," Aplikasi E-Marketing Panglong Kayu Menggunakan Metode Colaborative Filtering, Vol.11 no.1|Juni 2020.
[3] J. Wong, Internet Marketing for Beginners, Jakarta: PT Elex Media Komputindo, 2010.

[4] D. Irmawati, "Pemanfaatan E_Commerce Dalam Dunia Bisnis," Pemanfaatan E_Commerce Dalam Dunia Bisnis, Edisi Ke-Vi, November 2011.

[5] S. Kosasi, "Perancangan Sistem E-Commerce Untuk Memperluas Pasar," Perancangan Sistem ECommerce Untuk Memperluas Pasar, 2015.

[6] S. C. Vermaat, Discovering Computers Menjelajah Dunia Komputer Fundamental, Edisi 3, Jakarta: Salemba Infotek, 2007.

[7] A. T. Wibowo, "Pembuatan Aplikasi E-Commerce Pusat Oleh-Oleh Khas Pacitan Pada Toko Sari Rasa Pacitan," Pembuatan Aplikasi E-Commerce Pusat Oleh-Oleh Khas Pacitan Pada Toko Sari Rasa Pacitan, Ijns Volume 2 no 4 - Oktober 2013.

[8] [A. W. Yudah Yudhanto, Mudah Membuat dan Berbisnis Aplikasi Android dengan Android Studio, Jakarta: PT Elex Media Komputindo, 2017.

[9] W. S. A. S. M. I. J. T. R. A. D. Nazlina Izmi Addyna, "Pengolahan Data Penjualan Baju Online Pada Grosir Hasibuan Busana Pematangsiantar Berbasis Web," Pengolahan Data Penjualan Baju Online Pada Grosir Hasibuan Busana Pematangsiantar Berbasis Web, Vol. 2, (2020).

[10] P. B. S. M. C. Zandi Nugroho Hidayat1), "Perancangan Dan Implementasi Sistem ECommerce Dengan Menggunakan Cms Opencart Dalam Upaya Meningkatkan Penjualan Dan Pemasaran," Perancangan Dan Implementasi Sistem E-Commerce Dengan Menggunakan Cms Opencart Dalam Upaya Meningkatkan Penjualan Dan Pemasaran, Vol 2, No 1 (2014).

[11] A. Y. S. Deni Apriadi, "E-Commerce Berbasis Marketplace Dalam Upaya Mempersingkat Distribusi Penjualan Hasil Pertanian," E-Commerce Berbasis Marketplace Dalam Upaya Mempersingkat Distribusi Penjualan Hasil Pertanian, Vol 1, No 2 (2017): Agustus 2017.

[12] s. Diki Susandi, "Sistem Penjualan Berbasis ECommerce Menggunakan Metode Object Oriented pada Distro Dlapak Street Wear," Sistem Penjualan Berbasis E-Commerce Menggunakan Metode Object Oriented pada Distro Dlapak Street Wear, VOL. 4(2017).

[13] N. T. M. Indra Wati, Perancangan Sistem Penjualan E-Commerce Pada Toko Cahaya Busana, 2017. 